Revista Iberoamericana, Vol. LXXVII, Núms. 236-237, Julio-Diciembre 2011, 813-828

\title{
DEL BOOM Y MÁS ALLÁ: LA FICCIONALIZACIÓN DEL FRACASO EDITORIAL EN EL JARDÍN DE AL LADO DE JOSÉ DONOSO Y BASURA DE HÉCTOR ABAD FACIOLINCE
}

\author{
POR \\ Ana María Mutis \\ Denison University
}

No termina de asimilarse el avasallador éxito literario y comercial del llamado boom latinoamericano cuando críticos y escritores ya buscan definir tanto los límites temporales como los lineamientos temáticos y estilísticos de este acontecimiento literario, a la vez que discuten sus repercusiones en la narrativa latinoamericana. ${ }^{1}$ Una preocupación recurrente en algunas de estas discusiones fue el problema de la exclusiones producidas en las dos décadas del boom; coinciden los estudiosos en reconocer que la literatura de mujeres, la producida en América Central y Brasil, y de manera más amplia, la literatura que no se adhería al discurso dominante del momento, no pudieron sacar provecho del crecimiento expansivo de la industria editorial de aquellos años. Los excluidos, explica Elizabeth Garrels, "eran borrados de la literatura de diferentes maneras. Si bien podían leer y escribir, había obstáculos que les dificultaban la producción, la publicación y el consumo" (322).

El jardín de al lado (1981), de José Donoso y Basura (2000), de Héctor Abad Faciolince construyen una ficción alrededor de estos "borrados de la literatura" al narrar la historia del escritor fracasado que no pudo conquistar el éxito editorial que lograron los miembros del boom. Pero más allá de una semejanza temática, en ambas novelas puede leerse una reflexión teórica sobre este fenómeno comercial en las letras latinoamericanas y, en general, sobre el papel del mercado editorial en la definición del valor literario. El estudio comparativo de El jardín y Basura permite identificar las coincidencias y las divergencias en la manera en que dos autores muy diferentes uno que formó parte del boom y otro que no, uno contemporáneo al boom y otro muy

\footnotetext{
1 Me refiero, por ejemplo, al coloquio que tuvo lugar en Washington D.C. en 1979 para discutir "El surgimiento de la nueva narrativa latinoamericana, 1950-1975” y del cual se publicó el libro Más allá del boom: literatura y mercado en 1981, título que inspira el del presente trabajo. El boom ha sido ampliamente analizado por numerosos críticos entre los que se encuentran Ángel Rama, Donald L. Shaw, David Viñas, Randolph Pope, y más recientemente Brett Levinson, Idelber Avelar y Diana Sorensen.
} 
posterior, uno de amplia trayectoria literaria y el otro perteneciente a la nueva generación de escritores colombianos- entienden tanto el boom como la evolución de la literatura latinoamericana a partir de este momento. La distancia y los puntos de encuentro entre las dos ficcionalizaciones de un mismo evento editorial favorecen la exploración de dos miradas desiguales y dos apreciaciones distintas de un mismo momento en la historia de la literatura latinoamericana así como del papel del escritor y de la maquinaria editorial frente a la sociedad.

La presencia e importancia del tema del boom latinoamericano en El jardín ha sido comentada por algunos críticos, quienes han encontrado un paralelo entre esta novela y las observaciones que José Donoso hiciera sobre el mismo tema en Historia personal del "boom". Entre estos trabajos sobresalen los de Oscar Montero y Nadine Dejong. Oscar Montero señala que "La lectura de un texto orienta la del otro y su contrapunto contribuye al estudio de un aspecto de la práctica literaria contemporánea que no se termina de estudiar: la relación del escritor a la sociedad, su posición frente al reconocimiento o desprecio que ésta pueda otorgarle según el valor que se le ofrezca a sus textos” (450). Por su parte, Nadine Dejong encuentra que a partir del paralelo entre El jardín y la Historia personal se puede reconocer la presencia de una reflexión teórica en la novela (52). Si bien las correspondencias entre Historia personal y El jardín ayudan a comprobar la existencia de un aspecto teórico en la novela, no es indispensable acreditar este hallazgo por medio de las semejanzas de la ficción con el ensayo de Donoso; El jardín, por sí solo, presenta suficientes juicios literarios de los que puede extraerse una reflexión sobre la historia literaria latinoamericana, en particular sobre la figuración de la literatura del boom en esta historia.

El boom aparece desde las primeras páginas de El jardín cuando Julio Méndez, el escritor protagonista, lamenta verse obligado a transformar su novela-documento, ya rechazada por la editora Núria Monclús, en una obra que supere “a esa literatura de consumo, hoy tan de moda, que ha encumbrado a falsos dioses como García Márquez, Marcelo Chiriboga y Carlos Fuentes” (13). Los nombres de estos “falsos dioses” con el de Núria Monclús a la cabeza -personaje inspirado en la agente literaria Carmen Balcells-, se repetirán a lo largo de la novela y con frecuencia se agruparán bajo el apelativo de "mafia”, acusación que demuestra el resentimiento del narrador al verse excluido del prestigio y éxito editorial de este grupo. La insistencia de Julio Méndez en utilizar la palabra "mafia” para referirse a los escritores del boom es un signo claro de su envidia hacia estos escritores, pues como explica Donoso en Historia personal, la amistad entre los miembros del boom es "llamada mafia por aquellos que se sienten excluidos” (56).

Así como el rencor del narrador se hace patente en su uso de apelativos despectivos para referirse a los autores del boom, también se manifiesta en sus apreciaciones negativas de la literatura de estos escritores. Un juicio que aparece en estas líneas y que resurgirá

\footnotetext{
ISSN 2154-4794 (Electrónico)
ISSN 0034-9631 (Impreso)
} 
de manera recurrente en la narración es el de calificar a la literatura del boom como literatura de consumo, criticando así su éxito comercial. Ángel Rama explica el ataque a la maquinaria comercial del boom al observar que

La progresiva incorporación de la técnicas de la publicidad y el mercadeo a que se vio conducida la infraestructura empresarial cuando las ediciones tradicionales de tres mil ejemplares fueron sustituidas por tiradas masivas, dio paso a posiciones negativas, a reparos y objeciones que llegaron a adquirir una nota ácida. (53)

Según José Donoso en Historia personal, estas réplicas provinieron de escritores y críticos que no se vieron beneficiados del estallido comercial de esta nueva literatura (17), respuesta que Ángel Rama atribuye al hecho de que si los escritores excluidos arremetieron contra el aspecto comercial del boom y contra su carácter excluyente, los escritores triunfantes se defendieron "tildando a sus detractores de envidiosos, resentidos o fracasados” (54).

La novela de Donoso, más que recrear la pugna entre el boom y sus detractores, utiliza esta contienda para presentar el fenómeno del boom desde una óptica diferente: la del relegado. El boom se muestra en esta novela a través del filtro del excluido, por lo que presenta la literatura que hiciera famosos a Mario Vargas Llosa, Carlos Fuentes y Gabriel García Márquez, no a partir de sus características intrínsecas, sino desde los ataques que estas características suscitaron por parte de sus enemigos. Esto puede verse en que una de las acusaciones de Julio Méndez a la narrativa del boom es la de ser una literatura "con alardes de experimental" caracterizada por su "puro escepticismo" (Donoso, Jardín 46). La primera de estas críticas refiere a las innovaciones técnicas utilizadas por los escritores del boom y la segunda seguramente alude al "escepticismo de la mayoría de los nuevos novelistas en cuanto a la posibilidad de comprender la realidad" (Shaw, Nueva narrativa 245).

Otra de las críticas de Julio va dirigida al desarraigo de los escritores de este grupo hacia sus países, pues los señala de cosmopolitas que escriben de una realidad que desconocen desde la cómoda distancia del exilio voluntario (48). El desapego hacia la realidad latinoamericana que Julio le reprocha a los escritores del boom no se basa en su condición de exiliados -al fin y al cabo Julio también vive fuera de su país, al que no planea regresar aunque puede hacerlo-, ni en la ausencia de un verdadero compromiso político, del cual el mismo Julio adolece según su esposa y amigos. El reclamo de Julio tiene que ver con el hecho de que estos escritores no han vivido en carne propia la materia de su escritura. A diferencia de Julio, quien intenta infructuosamente transformar sus seis días de prisión a raíz del golpe militar en "la gran novela chilena”, los escritores del boom han dado a conocer a sus respectivos países en el exterior pese a su desconocimiento de "la experiencia de primera mano como participantes en una tragedia colectiva" (48). Como señala Alejandro Herrero-Olaizola, La caja sin secreto, obra maestra del ficticio

\footnotetext{
Revista Iberoamericana, Vol. LXXVII, Núms. 236-237, Julio-Diciembre 2011, 813-828
ISSN 2154-4794 (Electrónico)
} 
Marcelo Chiriboga, es una caja vaciada de contenido político, histórico o testimonial (336), y aún así, Julio reconoce que esta novela había exportado una imagen del Ecuador al mundo mucho más poderosa que toda la información publicada sobre este país (137).

Pero quizá la descripción más precisa de la literatura del boom en esta novela se cristaliza en la encrucijada literaria de Julio Méndez. Sus obras recientes, juzgadas por pertenecer a un mundo "demasiado doméstico y personal, carente de esa ambición totalizadora que caracteriza a la gran novela latinoamericana contemporánea” lo reducen a ser considerado un escritor de "tono menor" (36). Su aspiración es la de pasar al "tono mayor" al producir una gran novela latinoamericana que le permita el "salto a la trascendencia y la salvación” (36). Julio quiere contar la historia de su experiencia en el calabozo a raíz del Once y la editora catalana le sugiere que se aparte de la "crónica de sucesos que todo el mundo conoce y condena" a favor de una "metáfora válida en sí y no por lo que señala afuera de la literatura” (29).

Son dos los principales aspectos que oponen la literatura de Julio, de tono menor, a la literatura que comercializa la editora catalana, de tono mayor: el estilo de Julio es doméstico y personal en contraposición a la novela totalizadora del boom, y su tema está arraigado en la realidad en lugar de recurrir al solipsismo como, según Julio, lo hace la literatura auspiciada por Núria Monclús. El adjetivo “totalizadora” para definir la literatura del boom alude a su vinculación con el mito y con lo simbólico que arranca el discurso de la preocupación personal y local, y lo sitúa en un nivel metafísico. Mario Vargas Llosa, en uno de sus ensayos críticos sobre la narrativa de Gabriel García Márquez, define la novela "total" como aquella que busca "competir con la realidad de igual a igual, enfrentándole una imagen de una vitalidad, vastedad y complejidad cualitativamente equivalentes" (159). Es también una novela que "tiende, cada vez más, a explorar la condición humana y la angustia del hombre contemporáneo, en busca de nuevos valores” (Shaw, Nueva narrativa 244). De ahí que se entienda como "totalizadora" la narración que enfatiza su aspecto universal y humano por encima de consideraciones regionales o locales.

Sin embargo, se sabe que por ser "total" la narrativa del boom no desantendió los asuntos latinoamericanos. Por el contrario, la búsqueda de una identidad latinoamericana fue una preocupación central en la literatura del boom, pues como explica Frederick M. Nunn, los autores de este grupo siempremostraroninterés en definir la "latinoamericanidad" para crear una historia y una herencia común (4-5). Pero como en el empeño de definir la latinoamericanidad se traspasaron las fronteras nacionales, esta literatura privilegió una perspectiva continental por encima de una nacional, lo que llevó a reclamos como el de Julio de que esta narrativa estaba desligada de la realidad política y social de los países latinoamericanos. Fue también por su carácter "total” que, como ya mencioné, la literatura del boom se acercó a la realidad de una manera diferente, no con el ánimo de transcribirla sino, como dice Vargas Llosa, de crearle competencia. Donald L. Shaw explica que una de las características fundamentales de la literatura del boom fue su

Revista Iberoamericana, Vol. LXXVII, Núms. 236-237, Julio-Diciembre 2011, 813-828 ISSN 2154-4794 (Electrónico)
ISSN 0034-9631 (Impreso) 
escepticismo frente a la realidad, que la llevó a rechazar el realismo tradicional y en cambio optó por mostrar una nueva realidad más influida por la ambigüedad, el misterio y la fantasía que por los hechos cotidianos (Nueva narrativa 245).

El dilema literario de Julio es justamente cómo reconciliar la narración de una realidad local, personal, históricamente arraigada y políticamente comprometida con la ambición de trascendencia de las obras del boom, que en opinión de Núria Monclús solamente puede conseguirse por medio de un impulso totalizador que eleve su experiencia a la categoría de metáfora. Al menos así es como Julio interpreta las recomendaciones de Núria, pero al entregarle la nueva versión de la novela con los cambios sugeridos por ella, recibe con sorpresa que la editora rechaza su imitación fallida de los grandes escritores latinoamericanos, y que desaprueba su adjetivación recargada y su excesiva retórica. Las tres editoriales a las que Núria presenta la novela la rechazan por considerarla "un error de perspectiva y de gusto” (232) a lo que Núria agrega que prefiere la anterior versión a ésta.

El error de perspectiva de Julio reside no solamente en las cualidades intrínsecas de su novela sino en su posicionamiento dentro del ambiente literario del momento. Es claro que tanto Núria como las tres editoriales que rechazan la novela de Julio reprueban su imitación de un estilo que está de moda (o que estuvo de moda y ya no está, como el mismo Julio reconoce) y el hecho de que la novela no propone algo nuevo o diferente. La versión original, en cambio, proponía algo novedoso. Si miramos la descripción que Julio ofrece de su novela y de su estilo literario de "tono menor" encontramos una cierta afinidad con la literatura posterior al boom según la describe Antonio Skármeta. ${ }^{2}$ Según Skármeta, la literatura de su generación se caracteriza por su “convivencia plena con la realidad absteniéndose de desintegrarla para reformularla en una significación supra real” (273) y busca presentar el mundo como es. Julio manifiesta su deseo de transcribir fielmente la realidad cuando, indignado por las sugerencias de Núria Monclús, afirma: "Yo era otra cosa: yo había pasado seis días en un calabozo a raíz del Once ... y constituye una reserva de dolor que no necesita metáfora para ser válida: basta relatar los hechos” (30). Para Skármeta, la literatura de su generación es "intrascendente” y "vocacionalmente antipretenciosa” pues "más que reordenadora del mundo en un sistema estético congruente de amplia perspectiva, es simplemente presentadora de él” (274).

También el carácter documental de la novela de Julio, así como su contenido político, lo acercan a la narrativa del posboom. Como explica Shaw, los escritores de esta

2 Se habla de la literatura posterior al boom aunque se ha de reconocer que mientras el boom se estaba desarrollando ya el posboom estaba en etapa de gestación. Shaw propone como ejemplos tempranos de esta literatura a Gazapo (1965), de Gustavo Sainz y los relatos de Skármeta en El entusiasmo (1967). También La traición de Rita Hayworth (1968) y Boquitas pintadas (1969), de Manuel Puig fueron unas de las primeras obras del posboom (Nueva narrativa 265).

Revista Iberoamericana, Vol. LXXVII, Núms. 236-237, Julio-Diciembre 2011, 813-828
ISSN 0034-9631 (Impreso) 
generación son escépticos frente a la idea de que la innovación artística en la escritura opera en contra del status quo como creían los escritores del boom. Por eso, agrega Shaw, frente a los trágicos eventos ocurridos en Argentina, Chile, Uruguay y América Central, los escritores del posboom decidieron retornar a una ficción cimentada en el contenido, con énfasis en la denuncia y la protesta (Post-Boom 13). ${ }^{3}$

Julio, que dentro de su estilo doméstico y personal se adhería a los valores que Skármeta describe como característicos de la literatura del posboom, traiciona su forma de escritura en su ambiciosa búsqueda de trascendencia y en su fallido intento por alcanzar un “tono mayor”. Más grave aún es que con esta traición sella su fracaso, pues el modelo que él se empeña en emular ya no estaba en boga cuando intenta publicar su novela ya que para entonces solamente quedaba "el olor a pólvora y azufre que dejaron los cohetes del ‘boom’ después de estallar y apagarse” (31). La contradicción entre los lineamientos estilísticos que le impone Núria Monclús a Julio y la agonía de este estilo literario lleva a la pregunta: ¿Por qué habría de sugerirle la editora adherirse a un modelo que ya estaba caduco, o que estaba próximo a estarlo?

Una posible respuesta es que la adhesión al estilo del boom es una obsesión de Julio que él pone en boca de la editora catalana. Julio proyecta en Núria sus propias inseguridades literarias e interpreta sus sugerencias como una reafirmación de lo que él mismo piensa que debe tener su obra para lograr la trascendencia. Esto coincide con la opinión de Donoso, expresada en Historia personal, de que el boom "es una creación de la histeria, de la envidia y de la paranoia” (11). El boom en la novela de Donoso es más un espectro que asedia al protagonista llevándolo al fracaso literario que un obstáculo real en la publicación de su obra. De no ser así, ¿cómo explicar los términos

3 La discusión en torno al papel de la literatura del boom en la política de los países latinoamericanos y los procesos de globalización es discutida por Brett Levinson en su libro The Ends of literature. The Latin American "Boom" in the Neoliberal Marketplace. Explica Levinson que existen dos visiones a este respecto. Una de ellas ve el éxito internacional de la literatura del boom como un indicio del ingreso de Latinoamérica al escenario cultural internacional e interpreta la innovación estilística de esta literatura como prueba de que Latinoamérica ha superado su carácter local, atrasado y oprimido. La visión opuesta refuta esta posición a la vez que combate la percepción de que una mayor libertad estilística corra paralela a una mayor libertad política, pues considera que la revolución cultural del boom se prestó para políticas y economías conservadoras (22). La diferencia entre estos dos puntos de vista no niega la existencia de un deseo de cambio por parte de muchos escritores del boom. En A Turbulent Decade Remembered: Scenes from the Latin American Sixties, Diana Sorensen analiza la intersección entre la política y la estética de los años sesenta y encuentra que en muchas obras literarias de este periodo figura un deseo de transformación cultural y político, manifiesto en algunos casos en un diálogo entre una mirada nostálgica hacia el pasado y la creación de una nueva utopía. A riesgo de simplificar la discusión expuesta por Levinson, me atrevo a sugerir que en la aparente contradicción entre nostalgia y utopía reside posiblemente la divergencia entre las dos visiones planteadas por este crítico, pues si algunos ven en la mirada al pasado de la literatura del boom una tendencia conservadora, otros se concentran en el poder regenerador y de cambio presente en el modelo utópico utilizado por estos escritores.

Revista Iberoamericana, Vol. LXXVII, Núms. 236-237, Julio-Diciembre 2011, 813-828 ISSN 0034-9631 (Impreso) 
con que Núria Monclús rechaza su versión final de la novela? Incluso, ¿cómo se puede justificar que la editora publique la novela de Gloria, la cual retoma el estilo cotidiano que caracterizaba a la obra de Julio y que él con tanto esfuerzo buscaba superar en aras de seguir los lineamientos supuestamente planteados por la editora? La obra de Gloria no se adhiere a los parámetros de la novela totalizadora, sino que se instala en la cotidianidad, al mostrar la historia íntima de la derrota de un hombre en el plano profesional, pero también afectivo y familiar. Como bien nota Montero, "lo que escribe [Gloria] no es 'la gran novela de hoy' que Julio no pudo hacer, sino precisamente el relato del fracaso de Julio, usándolo a él de narrador y escribiendo sobre sí misma y el ambiente en que vive a través de la perspectiva del hombre” (463).

Otra posibilidad, que no excluye la anterior, es que la contradicción entre lo que Núria le sugiere a Julio y las exigencias del mercado sirva para elaborar una crítica punzante de la tiranía de la maquinaria editorial y de la arbitrariedad y volatilidad del gusto literario. Una mirada detenida al último capítulo da sustento a esta interpretación. En un giro inesperado, el último capítulo sugiere que todo lo narrado en El jardín no es obra de Julio sino de su esposa, quien para mayor agravio logra que su novela sea publicada por Núria Monclús. El fracaso de Julio se hace aún más perentorio pues a su voz extinguida no se le permite, ni siquiera, comunicar su propia derrota. El escritor frustrado lo es hasta tal punto que necesita de alguien que narre por él su fracaso, $\mathrm{y}$ ese alguien consigue usurpar su autoridad narrativa con la ayuda de la figura tiránica de Núria Monclús. ${ }^{4}$

El relevo del narrador al final de El jardín ha sido interpretado como un triunfo femenino sobre el poder narrativo masculino. Así lo entiende Lucille Kerr, quien ve en este "juego de substitución” una lucha de poder que al final gana la figura femenina, el sujeto de la narración, al apropiarse del poder narrativo de la figura dominante masculina (45). De similar parecer es Rosemary Geisdorfer Feal, quien ve en la escritura de Gloria una liberación de su papel de objeto de deseo masculino (410). Aunque en esta toma de poder convergen cuestiones de género y escritura, no se debe descuidar el hecho de que la publicación de la novela de Gloria inserta el triunfo femenino en el mundo comercial de la industria editorial. Como bien reconoce Kerr, la verdadera derrota de Julio no está en el hecho de perder el control de su propio texto, sino en que su trabajo

4 Lucille Kerr argumenta que la novela de Donoso expone un intrincado juego de autoridad que no nos permite localizar dónde reside la autoridad del texto. Dice Kerr que "The ultimate identity and locus of the authoritative subject or text, the source of authority itself, cannot be clearly defined here: authority seems to be generated everywhere and yet in no single place; it has no original or final place or person in which to reside” (60). Sin embargo, Kerr reconoce que es Núria Monclús quien tiene la última palabra, al ser ella quien rechaza la novela de Julio y acepta la de Gloria, al ser ella el lector para quienes ellos escriben y la persona que autoriza el final de la novela de Gloria (56-7). El poder de Núria Monclús en la novela representa el poder de la industria editorial en general, y de esta manera funciona como "the last authoritative word”, utilizando las palabras con que Kerr describe a la editora.

Revista Iberoamericana, Vol. LXXVII, Núms. 236-237, Julio-Diciembre 2011, 813-828
ISSN 0034-9631 (Impreso) 
no sea publicado (51). De igual manera, la victoria de Gloria sobre Julio no se limita a que lo suplanta y lo silencia, sino que consigue aquello que Julio no pudo lograr: la publicación y distribución de su novela de la mano de Núria Monclús.

Porque El jardín enhebra dentro de su ficción una reflexión teórica sobre la historia literaria latinoamericana, la publicación de Gloria al final de la novela viene a significar mucho más que el éxito individual de uno de sus personajes. Por ello, el triunfo de Gloria ha sido interpretado por algunos críticos como un anuncio por parte de Donoso de la emergencia de la literatura femenina en las letras latinoamericanas. Entre ellos se encuentra Herrero-Olaizola, quien dice que "Donoso fictionalizes the mechanisms of marketing literary success by an inversion of his own success into the failure of Julio, perhaps proposing that a new generation of Latin Americans writers, women in particular, are ‘taking over' the field of literary production” (332-33). Asimismo, Diana Sorensen afirma que elúltimo capítulo aborda los cambios de la literatura hispanoamericana a finales de los años setenta con la llegada de las escritoras mujeres, cuyas obras modificaron el panorama editorial de los años ochenta. ${ }^{5}$ Sin embargo, porque en la novela este triunfo ocurre a expensas de la derrota de Julio, deja un sabor amargo que la publicación de Gloria no hubiera dejado de haber sido una victoria sin víctimas.

El jardín, al exponer la voz del marginado en los primeros capítulos y luego aniquilarla con la última vuelta de tuerca, no se conforma con presentar los cambios en el gusto literario, sino argumenta que la realidad comercial de la industria editorial silencia las voces de quienes no se acomodan a los deseos volátiles y caprichosos del mercado, deseos que las editoriales pretenden representar. El gran error de Julio está en que se sabe comerciante además de artista, pero no puede conciliar las dos dimensiones de su oficio. Su "error de perspectiva" se constata en que su estilo se adhiere a los principios del posboom cuando la narrativa del boom estaba en furor, y luego busca emular el estilo de los escritores del boom cuando ya ha pasado de moda. Luego, en un giro irónico y cruel, su esposa se ve beneficiada de la emergencia de la literatura femenina y logra publicar una novela que Julio posiblemente hubiera podido escribir si no hubiera abandonado su estilo doméstico e íntimo.

Dice Oscar Montero que "Lo que sugiere [El jardín] es el estudio no sólo de los mecanismos de la producción narrativa, sino de la historia de esa producción y de su circulación en el mercado literario” (465). La idea de presentar esta historia desde la mirada rencorosa del escritor fracasado presenta la dificultad de hablar del fracaso desde el fracaso mismo, más aún cuando este fracaso se traduce en la ausencia de voz. ¿Cómo

\footnotetext{
5 En palabras de Sorensen, "The game of veils notwithstanding, Chapter Six is a kind of authorial deus ex machina that provides closure, introduces a dazzling sense of surprise, and, I would claim, also manages to slyly address some of the changes that obtained in the republic of Hispanic letters in the latter part of the 1970s, when the boom's command of authorship was facing the challenges posed by women writers whose books were reconfiguring the publishing landscape by the early 1980s” (161).

ISSN 2154-4794 (Electrónico)
ISSN 0034-9631 (Impreso)
} 
habla una voz que ha sido apagada? En su iluminador artículo, Priscila Meléndez expone la manera en que está representada la figura del palimpsesto en El jardín mediante la presencia de diversos textos que temática y formalmente chocan entre sí (201). La revisión, lo borrado, la reescritura, son operaciones que para Meléndez revelan la relación entre escritura y lectura. Pero también, propongo aquí, son maniobras que permiten recrear las acciones de la maquinaria editorial y al mismo tiempo preservar el escrito que nunca salió a la luz: lo que está escrito sobre lo borrado, el texto sobre el texto, es la única manera en la que podemos acceder al escrito que jamás conoceremos, el de Julio. Como mencioné anteriormente, Elizabeth Garrells se refirió, de manera muy apropiada, a los excluidos del boom como "borrados de la literatura" (322). Donoso da validez a esa expresión con una ficción que, desde la perspectiva del fracaso, traza un recorrido por la historia de la narrativa latinoamericana reciente y resalta la injerencia que en ella tiene la maquinaria editorial, una empresa que cobra sus víctimas borrando su escritura.

En Basura (2000), del escritor colombiano Héctor Abad Faciolince, se encuentra un tema similar al de El jardín. El protagonista Bernardo Davanzati es un escritor fracasado que tira todo lo que escribe a la basura de su edificio, y su vecino rescata los manuscritos de dentro de los desperdicios para hacer con ellos un libro. Basura se nos presenta como el libro que el vecino construye al recopilar los escritos de Davanzati e incluir sus propios comentarios. El narrador comienza por describir a Davanzati como un escritor que en los años sesenta publicó un par de novelas que no se vendieron por ser "las obras desconocidas de un desconocido" (13). En los primeros manuscritos que recupera el vecino Davanzati explica a través de referencias escatológicas que su deseo de escribir no corresponde a un afán de publicar y de conseguir beneficios económicos, sino a una urgencia casi biológica. Reconoce además que "Si lo publicara, admitiendo que alguien me lo quisiera publicar, lo primero que pensarían los críticos es que busco algún honor, reconocimiento, notoriedad, fama, plata. Y sí, eso es lo que buscan casi todos, eso es lo que yo mismo buscaba en otros tiempos" (21). Ya en las primeras páginas escritas por Davanzati aparece la cuestión del escritor que debe enfrentarse al aspecto comercial de su oficio. Davanzati se distancia del grupo de autores que escriben buscando reconocimiento y se define como un escritor con una vocación tan fuerte que supera cualquier consideración práctica. Algunos días después de recoger este texto, el vecino encuentra nuevos manuscritos en los cuales lee una crítica implacable contra la literatura de Gabriel García Márquez, en particular contra su uso del realismo mágico.

A primera vista, la semejanza más notoria entre Basura y El jardín es que las dos novelas se centran en la figura del escritor que, a pesar de ser contemporáneo a los autores del boom, no tiene acceso al éxito editorial de sus colegas. Davanzati, al igual que Julio Méndez, luchó por producir una novela con los rasgos que dieron prestigio a los escritores del boom pero que llevara la rúbrica de un estilo personal. Uno de sus libros, Diario de un impostor, "peca, quizá de un marcado experimentalismo (de ese que estaba tan en boga por los años sesenta)" (16) pero a la vez "está lleno de agudas

Revista Iberoamericana, Vol. LXXVII, Núms. 236-237, Julio-Diciembre 2011, 813-828
ISSN 0034-9631 (Impreso) 
observaciones cotidianas” (17). La búsqueda de un formato híbrido que presente un estilo propio pero que también incorpore la fórmula exitosa del boom resulta, al igual que en el caso de Julio Méndez, en el fracaso editorial.

Por otra parte, la diferencia más evidente en el tratamiento del tema del boom en las dos novelas es que en Basura éste no está representado por un grupo de nombres sino por un único personaje: Gabriel García Márquez. La saña de Davanzati no va dirigida a la "mafia" de escritores sino a una única persona, lo cual se explica en el hecho de que, como afirma Rafael Humberto Moreno Durán, "es inevitable hablar de García Márquez como frontera insalvable en cualquier panorámica que se haga de la literatura colombiana de las últimas décadas” (183). Con frecuencia los escritores colombianos se ven abocados a escribir bajo la sombra de García Márquez y a definir su arte en relación al estilo de este escritor. Esta realidad se evidencia en la pregunta obligada de toda entrevista: ¿Qué opinión tiene de Gabriel García Márquez? Por este motivo, y quizá también porque Davanzati vive en Colombia y no en Barcelona, donde el renombre de los escritores del boom no recae en una sola figura, la envidia del protagonista de la novela de Abad Faciolince es inspirada por un solo personaje. ${ }^{6}$

Es útil reconocer que si bien la crítica de Davanzati contra García Márquez es encarnizada, como afirma su vecino-editor, Davanzati no la formula a título personal sino que la pone en boca del protagonista de una de sus ficciones. Esta ficción cuenta la historia de Serafín Quevedo, a quien el vecino considera el "álter ego" de Davanzati. Serafín Quevedo, como su creador Davanzati, es un escritor que no ha contado con el triunfo editorial de su contemporáneo García Márquez y por ello siente una mezcla de admiración y resentimiento por este autor, sentimiento muy similar al que experimenta Julio Méndez por el ficticio Marcelo Chiriboga.

El ataque de Serafín Quevedo contra García Márquez se dirige principalmente contra dos rasgos de su literatura que están relacionados: el realismo mágico y el distanciamiento de la realidad. Contra el realismo mágico de García Márquez, Serafín Quevedo “[...] decía que era necesario deshacerse de la magia, despojar al país del espejismo de las supuestas maravillas inventadas por él. Decía que para el pantano del subdesarrollo era nefasto ese regodeo folclórico en historias de alucinada hermosura” (58). Pero sus críticas más agudas se enfocan en la falta de contacto de la prosa de García Márquez con la realidad nacional. Una de las narraciones de Serafín expone la diferencia entre la realidad colombiana -que él busca presentar en su obra- y las invenciones fantásticas de García Márquez. Señala Serafín que él creció en Medellín, una ciudad donde "la gente se moría a machetazo limpio o simplemente a bala” (58), y que este lugar nada tenía en común con Macondo:

6 Un reportaje por Juan Forero publicado en The New York Times en abril 6 del 2003, que trata de las diferencias entre los nuevos novelistas colombianos y García Márquez menciona la dificultad que para los primeros presenta el que su obra sea comparada constantemente a la del Nobel colombiano.

ISSN 0034-9631 (Impreso) 


\begin{abstract}
Allá no había vírgenes que ascendieran a los cielos ni el mundo era reciente ni las cosas carecían de nombre y había que señalarlas con el dedo; al contrario, en cada cosa se había incrustado ya una armadura indeleble de prejuicios. Lo único macondiano era que en la ciudad más violenta del mundo yo tuviera trece años y no conociera un muerto todavía. Mi padre me dijo que si no quería vivir de espaldas a la realidad, como los novelistas, era mejor que empezara a acostumbrarme. (59)
\end{abstract}

La observación del padre de Serafín coincide con la recriminación de Julio Méndez de que los escritores del boom se mantienen alejados de la realidad nacional. Pero ante todo, concuerda con lo que algunos críticos han llamado el rechazo del realismo por parte del boom que, como explica Shaw, resultó en "La tendencia a subordinar la observación a la fantasía creadora y la mitificación de la realidad” (Nueva narrativa 244).

Igualmente, en la diatriba de Serafín Quevedo contra la obra de García Márquez se puede leer un reclamo hacia el hecho de que ésta se haya considerado representativa de una identidad colombiana y latinoamericana. La vida rural retratada por García Márquez dista de ser la realidad urbana vivida por Serafín Quevedo y plasmada en sus obras. Difiere también de la realidad presentada por el propio Davanzati, cuya obra leemos en los manuscritos recopilados por el narrador. Los eventos presentados en los escritos de Davanzati tienen lugar en Medellín y narran, no eventos maravillosos, sino sucesos cotidianos.

Otra objeción que tiene Serafín Quevedo contra la literatura de García Márquez, es la presencia de la nostalgia en su obra. El momento en que en Cien años de soledad el coronel Aureliano Buendía recuerda frente al pelotón de fusilamiento la tarde en que su padre lo llevó a conocer el hielo es interpretado por Luz Mary Giraldo como una evocación del paraíso de la infancia, es "el retorno a los orígenes en el mito del paraíso perdido" (Ciudades 12). Serafín muestra su desconfianza frente a un pasado mejor, y de paso frente a la posibilidad de un mejor futuro, cuando afirma con sarcasmo: "Yo no sé cuándo conocí el hielo pues yo nací en los tiempos de la nevera. Me acuerdo, sí, de una mañana en que mi padre me llevó a conocer un muerto” (58).

En Basura, como en El jardín, la literatura del boom se presenta desde la perspectiva del escritor fracasado, óptica que permite no solamente la elaboración de una fuerte crítica a sus rasgos estilísticos y a su naturaleza excluyente, sino apunta hacia la presencia de otros tipos de literaturas que no merecieron la misma atención, señalándose de esta manera la volatilidad y tiranía del mercado editorial. También las dos novelas utilizan el tema del fracaso editorial para presentar la emergencia de una nueva literatura que se opone a la del boom. Así como en la novela de Donoso la publicación de Gloria recrea el triunfo de la literatura personal, íntima, escrita por mujeres, que aparece con gran fuerza en los años setenta y ochenta en las letras hispanoamericanas, la novela de Abad Faciolince anuncia el surgimiento de una nueva literatura colombiana.

\footnotetext{
Revista Iberoamericana, Vol. LXXVII, Núms. 236-237, Julio-Diciembre 2011, 813-828
ISSN 2154-4794 (Electrónico) 
De manera similar a El jardín, Basura termina con la publicación de un escrito, el del vecino de Davanzati, quien recopila y edita sus textos en un libro que consigna la historia de su fracaso. Los escritos de Davanzati, además de coincidir con los planteamientos de Skármeta sobre el posboom, exhiben características de la literatura colombiana reciente. El mejor ejemplo es su relato "La virgen manca" en el que narra la historia de una mujer que sostiene relaciones afectivas con cinco misioneros norteamericanos hasta que uno de ellos es secuestrado por la guerrilla y sus captores le piden doce millones de dólares por su rescate (129-45). Con su literatura afincada en la realidad política colombiana, Davanzati busca desbancar las utopías que hicieran famoso a Gabriel García Márquez y abordar la realidad desde el presente. El interés de Gabriel García Márquez por reconstruir el ayer, por explicar un país o una región a partir de su historia, no tiene eco en la literatura de los nuevos escritores ni en la de Davanzati. Como explica Luz Mary Giraldo, los nuevos escritores colombianos expresan su participación en el mundo "y buscan contar historias propias de la vida cotidiana, reconociéndose contemporáneos y demostrando que su país pertenece a la llamada 'aldea global'” ("De la utopía” 146 ).7

A través de los escritos de Davanzati la novela de Abad Faciolince presenta el surgimiento de una nueva literatura colombiana, preocupada por la realidad urbana y la situación social y política, y con un estilo y argumentos truculentos. Otra característica de la literatura de Davanzati es la variedad de géneros que acoge pues, como reconoce el narrador, Davanzati "cambiaba de género como quien cambia de camisa, en el intento de escribir algo ameno, o algo comprometido con su ciudad, o algo legible" (108). La pluralidad de formas que toma la obra de Davanzati concuerda con una de las características que Luz Mary Giraldo identifica en la literatura colombiana al final del siglo xx. La "multiplicidad" es el nombre que Giraldo da a "la convivencia de tonos, la arbitrariedad de determinados gestos, el énfasis en lo erótico y lo lúdico, la burla, la irreverencia y la desacralización, lo popular y lo culto, lo selecto y lo kitsch, la voluntad de estilo, de desorden o de fábula, la multiplicidad fragmentada, la recusación de la historia y la trivialización del arte y de la vida" ("Fin de siglo" 36).

Muchos de estos atributos aparecen en los relatos de Davanzati pero quizá el más notorio es el de la "multiplicidad fragmentada" que se concreta en narraciones breves, muchas veces inconclusas. Cuando el vecino de Davanzati recoge sus manuscritos de

\footnotetext{
7 Es importante aclarar que Giraldo habla de dos generaciones de escritores colombianos posteriores a Gabriel García Márquez: "La primera que surge al final de los años setenta tiene como principal característica su afán por despedir a Macondo, por abandonar las utopías, distanciarse de lo rural y volcar sus miradas hacia las ciudades. La segunda generación, formada por escritores nacidos entre 1960 y 1975, tiene un interés en lo inestable y lo truculento, y cuentan sus historias cotidianas "sin rendir tributo a ningún pasado ni romper con antecesores inmediatos” (“De la utopía” 146). Para efectos de este análisis no he tenido en cuenta esta división pues en la literatura de Davanzati se asoman rasgos de las dos generaciones.

Revista Iberoamericana, Vol. LXXVII, Núms. 236-237, Julio-Diciembre 2011, 813-828
ISSN 2154-4794 (Electrónico)
} 
los desperdicios encuentra que el escritor no escribe una novela completa. Más aún, cada texto termina en punta, sin un final definido que dé cierre al relato. Aunque la dificultad para escribir un texto completo se presenta como un indicativo más de su fracaso como escritor, también revela una prosa fragmentada más afín con la literatura colombiana de las últimas décadas que con los grandes relatos que caracterizaron la literatura del boom. ${ }^{8}$

La presencia de estas características en la literatura de Davanzati ofrece una posible explicación de por qué su obra no pudo conseguir el éxito editorial en los años sesenta: como en el caso de Julio en El jardín, su obra se adelanta al momento histórico en que se produce pues se anticipa a la nueva corriente de escritores que surgirá unas décadas más tarde. De ahí que este personaje, que en realidad se llama Marco Tulio Jaramillo, cambie su nombre a "Davanzati”, en clara alusión a la novedad y audacia de su arte. Luego, años más tarde, cuando su literatura hubiera podido ser publicada por ser más afín al gusto literario del momento, Davanzati encuentra que ya no le interesa publicar, que no le importa escribir más que para él mismo. Es gracias a su vecino que sus textos son publicados al final de la novela, lo que sugiere que el mercado literario actual es el escenario propicio para que los textos de Davanzati lleguen al público lector.

Se pudiera pensar que el final "feliz” de Basura vindica a la industria editorial de los cargos que El jardín le imputa con respecto a su intransigencia, sin embargo este final esconde una crítica aguda hacia su papel en los últimos años. Sabemos por los comentarios del narrador $-\mathrm{y}$ por las conclusiones que como lectores sacamos de los escritos de Davanzati-, que sus textos son de dudosa calidad, o al menos de calidad variable. El narrador insiste a lo largo de la novela que su vecino no es un gran escritor, pues su literatura sufre de ocasionales "caídas en una literatura deleznable, sosa, impublicable, en una literatura que no se merecía otro nombre que basura” (86). Lo curioso, entonces, es que pese a su mediocridad estos textos merezcan la publicación. Si en El jardín Donoso señala la opresión de la industria editorial que acalla ciertas voces de manera arbitraria, Abad Faciolince insinúa la reciente relajación de los estándares

8 La presencia de la literatura colombiana reciente en Basura toma forma no sólo a través del estilo literario de Davanzati, sino de las frecuentes insinuaciones autobiográficas presentes en el texto. Así como Serafín Quevedo es la "máscara juvenil” de Davanzati según el narrador, también lo es de Abad Faciolince. Un ejemplo es que el padre de Serafín Quevedo, como el Abad Faciolince, era médico y muere asesinado. Pero es el episodio en el que el padre de Serafín lo lleva a conocer un muerto que reproduce de manera idéntica la experiencia vivida por Abad Faciolince, plasmada en su obra autobigráfica El olvido que seremos (134-6). Otro giro autoreferencial, esta vez cómico, es cuando el narrador enumera aquellos nombres de pila que aseguran el fracaso literario, y entre ellos menciona a "Héctor" (125). También se pueden reconocer rasgos de otros escritores colombianos en la figura de Davanzati, como cuando conocemos que a Davanzati le interesa la biología y que le atrae más la ciencia que la literatura (168), comentario que hace alusión a Fernando Vallejo, licenciado en biología que ha escrito sobre esta materia.

\footnotetext{
Revista Iberoamericana, Vol. LXXVII, Núms. 236-237, Julio-Diciembre 2011, 813-828
ISSN 2154-4794 (Electrónico)
} 
de publicación que permite que cualquier obra sea publicable. Un revelador comentario es el de la amiga de Davanzati quien luego de reprocharle a su vecino el "perseguir los sobrados de un mediocre banquete" le sugiere que se deshaga cuanto antes de esos escritos, o mejor aún, que los publique, como si las dos operaciones fueran equivalentes en dificultad y propósito (188).

Por supuesto, aquello que se publica no es la obra de Davanzati, sino la de su vecino que apoyado en el material que recoge de la basura elabora una indagación sobre el fracaso, una exploración psicológica de la derrota de un hombre. Pero la fuerte presencia de la voz de Davanzati en el texto final, a diferencia de El jardín en la que vagamente se asoman las huellas de la novela de Julio, indica una revaluación de lo que la industria considera puede vender al público lector. Basura propone que la industria editorial actual ha creado un espacio para deshacer lo borrado y permitirle, como dice el narrador, "rescatar del silencio las palabras de un mudo" (180) aunque estas palabras sean de escaso valor. ${ }^{9}$

La pregunta que surge es, si los relatos de Davanzati logran ser publicados al final de la novela, ¿puede considerarse Basura una novela sobre el fracaso editorial? En efecto, el fracaso del escritor es el germen de la novela que apoyada en esta figura traza una trayectoria desde las exclusiones a las que fueron sujetas las voces que no pertenecían al discurso dominante en los años sesenta hasta la reciente legitimación de estas escrituras. La validación de estas voces al final de la novela exige una representación diferente a la del palimpsesto utilizado por Donoso, pues no refiere a un mercado editorial que borra ciertos discursos y escribe encima de ellos, sino que está dispuesto a recuperar lo borrado. Por ello, Abad Faciolince presenta un diálogo entre el narrador y los escritos que rescata de la basura, en lo que puede considerarse una vindicación de aquellas voces antes silenciadas.

Pero por encima de las diferencias en las miradas que Donoso y Abad Faciolince dan al fenómeno del boom en sus ficciones sobresale la más notoria de sus coincidencias: la elección de presentar el boom desde la perspectiva del excluido. Algunas posibles

9 Abad Faciolince comenta el éxito editorial de la literatura colombiana reciente en "Veinte años de compañía" en donde asegura que decenas de nuevos escritores colombianos "reciben anticipos editoriales que les permiten vivir del oficio, y unos cuantos puñados han sido publicados en el primer mundo, traducidos a diferentes idiomas y distribuidos en muchos países. Comparado con el frente político, con el de la guerra, el de la industria, el petróleo o el café, la literatura colombiana no está en crisis”. El éxito editorial no sólo se ha visto en las ventas logradas por estos escritores, sino en los premios que han obtenido. Para citar sólo algunos casos, Jorge Franco obtuvo el premio Hammett de Literatura Negra por Rosario Tijeras, Mario Mendoza obtuvo por primera vez para Colombia el Premio Biblioteca Breve Seix Barral y Basura de Héctor Abad Faciolince recibió el premio de novela Lengua de Trapo. Más recientemente el escritor colombiano William Ospina recibió el Premio Rómulo Gallegos 2009, Angela Becerra obtuvo el Premio Iberoamericano Planeta-Casa de América de Narrativa 2009 y Laura Restrepo consiguió el Premio Alfaguara de Novela en el año 2004 por su novela Delirio.

Revista Iberoamericana, Vol. LXXVII, Núms. 236-237, Julio-Diciembre 2011, 813-828 ISSN 0034-9631 (Impreso) 
explicaciones a esta convergencia han sido sugeridas a lo largo de este escrito. Hemos visto que para presentar una reflexión sobre este fenómeno literario en su relación con la industria editorial y con las preocupaciones artísticas de los escritores, el punto de vista del marginado favorece una postura crítica frente al boom que demuestra la necesidad de dejarlo atrás. En El jardín, el boom representa un momento en la historia literaria latinoamericana que debe ser superado, y en Basura se da esperanza al escritor colombiano que quiere escribir una literatura que rompa el modelo de García Márquez, pero se siente ofuscado ante el peso de su sombra. Asimismo, mediante el uso de esta perspectiva, estas novelas reconocen la existencia de literaturas ausentes, inéditas y emergentes. Pero de manera más amplia, al articular el tema del boom a partir del fracaso, Donoso y Abad Faciolince coinciden en considerar que la derrota ofrece una posición privilegiada desde la cual puede observarse este suceso literario, observándolo desde afuera, desde el escepticismo frente al éxito que solamente consiguen aquellos para quienes es esquivo.

\section{OBRAs CITADAS}

Abad Faciolince, Héctor. Basura. Madrid: Lengua de Trapo, 2000. El olvido que seremos. Bogotá: Planeta, 2006.

"Veinte años de compañía". La Jornada 19 oct. 2002. <http://www.jornada. unam.mx/2003/10/19/sem-abad.html>. 1 dic. 2010.

Avelar, Idelber. The Untimely Present: Postdictatorial Latin American Fiction and the Task of Mourning. Durham: Duke UP, 1999.

Dejong, Nadine. “José Donoso: El Boom entre ensayo y ficción”. Boletín de la Academia Argentina de Letras 65/255-256 (2000): 29-56.

Donoso, José. El jardín de al lado. Santiago de Chile: Alfaguara, 1996. Historia personal del "boom”. Barcelona: Seix Barral, 1983.

Feal, Rosemary Geisdorfer. "Donoso’s Interartistic Dialogue in El jardín de al lado”. MLN 103/2 (1988): 398-418.

Forero, Juan. "New Generation of Novelists Emerges in Colombia". The New York Times. 6 abril 2003.

García Márquez, Gabriel. Cien años de soledad. Jacques Joset, ed. Madrid: Cátedra, 2002.

Garrels, Elizabeth. “Resumen de la discusión”. Más allá del boom: literatura y mercado. México: Marcha, 1981. 289-326.

Giraldo, Luz Mary. Ciudades escritas. Literatura y ciudad en la narrativa colombiana. Bogotá: Convenio Andrés Bello, 2004.

"De la utopía al escepticismo: tres promociones y treinta años de narrativa en Colombia”. Hojas universitarias 52 (2002): 141-52.

ISSN 0034-9631 (Impreso) 
“Fin de siglo XX: por un nuevo lenguaje (1960-1996)". Literatura y cultura. Narrativa colombiana del siglo XX. Vol. 2. María Mercedes Jaramillo, Betty Osorio y Angela Inés Robledo, eds. Bogotá: Ministerio de Cultura, 2000. 9-48.

Herrero-Olaizola, Alejandro. "Consuming Aesthetics: Seix Barral and Jose Donoso in the Field of Latin American Literary Production”. MLN 115/2 (2000): 323-39.

Kerr, Lucille. “Authority in Play: José Donoso's El jardín de al lado”. Criticism: A Quarterly for Literature and the Arts 25/1 (1983): 41-65.

Levinson, Brett. The Ends of Literature: the Latin American "Boom" in the Neoliberal Marketplace. Stanford: Stanford UP, 2001.

Meléndez, Priscila. "Writing and Reading the Palimpsest: Donoso's El jardín de al lado”. Symposium: A Quarterly Journal in Modern Literatures 41/3(1987): 200-13.

Montero, Oscar. "El jardín de al lado: la escritura y el fracaso del éxito.” Revista Iberoamericana 49/123-124 (1983): 449-67.

Moreno Durán, Rafael Humberto. “Grandeza y miseria del cuento colombiano en las últimas décadas”. Literatura colombiana hoy: imaginación y barbarie. Karl Kohut, ed. Frankfurt: Vervuert, 1994. 183-8.

Nunn, Frederick M. Collisions with History: Latin American Fiction and Social Science: from El Boom to the New World Order. LatinAmerican Series. Athens: Ohio UP, 2001.

Pope, Randolph.

Rama, Ángel. “El ‘boom’ en perspectiva”. Más allá del boom: literatura y mercado. México: Marcha, 1981. 51-110.

Shaw, Donald L. Nueva narrativa hispanoamericana: Boom. Posboom. Posmodernismo. Madrid: Cátedra, 1999.

The Post-Boom in Spanish American Fiction.Albany: State U of New York P, 1998.

Skármeta, Antonio. “Al fin y al cabo, es su propia vida la cosa más cercana que cada escritor tiene para echar mano”. Más allá del boom: literatura y mercado. México: Marcha, 1981. 263-85.

Sorensen, Diana. A Turbulent Decade Remembered: Scenes from the Latin American Sixties. Palo Alto: Stanford UP, 2007.

Vargas Llosa, Mario. “García Márquez: de Aracataca a Macondo”. La novela hispanoamericana actual: compilación de ensayos críticos. Angel Flores y Raúl Silva Cáceres, ed. Long Island City: Las Américas, 1971. 157-75.

ISSN 2154-4794 (Electrónico)
ISSN 0034-9631 (Impreso) 